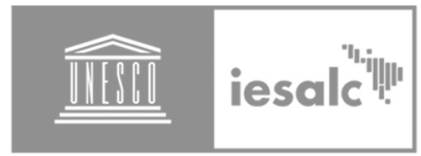

\title{
Unesco
}

Instituto Internacional

para la Educación Superior

en América Latina

y el Caribe
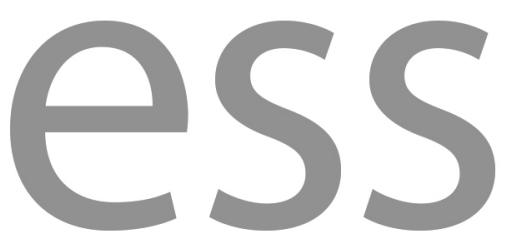

?

Educación

Superior y

Sociedad

Vol. 33 No. 2 (2021)

-

$\bullet$

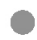

$\bullet$
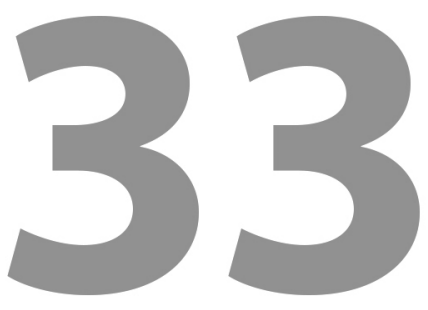

Incluye Dossier Temático:

Desafíos de la educación superior frente a la pandemia de Covid-19 en América Latina y el Caribe 


\section{Agenda 2030 e Desenvolvimento Sustentável: avanços e desafios da Educação Superior no Brasil}

Stela Maria Meneghel, Fabrício Filisbino, Ana Cristina Adry Moura de Argôllo

\section{RESUMO}

Este artigo analisa indicadores da Educação Superior (ES) do Brasil, um dos países mais desiguais do mundo, em sua possibilidade de contribuir com a Agenda 2030. A análise, de cunho bibliográfico e documental, considera a expansão de matrículas focando: o acesso da população baixa renda; a diversidade racial; e o acesso do estudante com deficiência. Os dados mostram que, apesar do crescimento do setor privado-mercantil, políticas de ação afirmativa (PAA) geraram avanços significativos, revelando a importância de diretrizes ODS para manutenção e aperfeiçoamento de políticas públicas de ES voltadas à inclusão e redução da desigualdade.

Palavras-chave: Agenda 2030; Educação Superior Brasileira; Inclusão; Diversidade; Políticas de Ação Afirmativa.

\section{Agenda 2030 and Sustainable Development: progress and challenges of Higher Education in Brazil}

\section{ABSTRACT}

This article analyzes indicators of Higher Education (HE) in Brazil, one of the most unequal countries in the world, in its ability to contribute to the 2030 Agenda. The analysis, of bibliographic and documentary nature, considers the expansion of enrollments focusing on: access for the low-income population; racial diversity; and access for students with disabilities. The data show that, despite private-market growth, affirmative action policies (AAP) have generated significant progress, revealing the importance of SDG guidelines for maintaining and improving public HE policies aimed at inclusion and reducing inequality.

Keywords: Agenda 2030; Brazilian Higher Education; Inclusion; Diversity; Affirmative Action Policies. 


\section{Agenda 2030 y Desarrollo Sostenible: avances y desafíos de la Educación Superior en Brasil}

\section{RESUMEN}

Este artículo analiza los indicadores de Educación Superior (ES) en Brasil, uno de los países más desiguales del mundo, en su capacidad de contribuir a la Agenda 2030. El análisis, de naturaleza bibliográfica y documental, considera la expansión de las inscripciones centradas en: acceso de la población de bajos ingresos; diversidad racial; y acceso de estudiantes con discapacidades. Los datos muestran que, a pesar del crecimiento del mercado privado, las políticas de acción afirmativa (PAA) han generado avances significativos, revelando la importancia de las directrices ODS para mantener y mejorar las políticas públicas de educación superior dirigidas a la inclusión y a reducir la desigualdad.

Palabras clave: Agenda 2030; Educación Superior Brasileña; Inclusión; Diversidad; Políticas de Acción Afirmativa.

\section{Agenda 2030 et développement durable: avancées et défis de l'enseignement supérieur au Brésil}

\section{RESUMÉ}

Cet article analyse les indicateurs de l'enseignement supérieur (ES) au Brésil, I'un des pays les plus inégaux au monde, dans sa possibilité de contribuer à I'Agenda 2030. L'analyse, de nature bibliographique et documentaire, considère l'expansion des inscriptions en se centrant sur: l'accès de la population à faible revenu; la diversité raciale; et l'accès aux étudiants handicapés. Les données montrent que, malgré la croissance du marché privé, les politiques d'action positive (PAP) ont généré des avancées significatives, révélant l'importance des lignes directrices ODD pour maintenir et améliorer les politiques publiques d'enseignement supérieur visant à l'inclusion et à la réduction des inégalités.

Mots clés: Agenda 2030; Enseignement Supérieur Brésilien; Inclusion; Diversité; Politiques d'Action Positive. 


\section{INTRODUÇÃO}

\section{A Agenda 2030, a desigualdade e o papel da ES na América Latina}

A erradicação da pobreza e a redução das desigualdades mundiais no acesso aos bens produzidos pela humanidade foram, nas últimas décadas, dois dos principais objetivos dos organismos internacionais. Nesse sentido, a Organização das Nações Unidas (ONU) aprovou, na Cúpula do Milênio (2000), o estabelecimento dos Objetivos de Desenvolvimento do Milênio - 2001-2015 (ODM) - documento considerado por alguns autores o mais bem-sucedido esforço coletivo de combate à pobreza, por estimular os países ricos a colaborarem com os países pobres, ao mesmo tempo em que busca o compromisso dos países menos desenvolvidos na elevação do desenvolvimento humano (Carvalho, 2014).

Mas, não obstante a adoção dos ODM tenha gerado avanços, suas metas não foram plenamente atingidas, quer pelo horizonte temporal estabelecido de 2001 a 2015, quer pela complexidade do mundo globalizado. Visando renovar o compromisso com sua efetivação, foi realizada a Conferência das Nações Unidas sobre Desenvolvimento Sustentável, em junho de 2012 (a Rio+20), quando foram estabelecidos novos parâmetros para uma agenda mundial pós2015. O documento final do evento, O Futuro que Queremos, renovou o objetivo de construção de um sistema mais justo e igualitário, renovando compromissos e responsabilidades de todos os países da ONU - tanto desenvolvidos quanto em desenvolvimento (Roma, 2019).

O plano de ação para a consecução dos novos ODS, Transformando Nosso Mundo: A Agenda 2030 para o Desenvolvimento Sustentável, ou apenas Agenda 2030, passou a conter 17 objetivos e 169 metas, cuja execução levaria à melhoria das condições de vida da população vulnerável. Esta agenda deve ser concretizada no prazo de 15 anos, contabilizados a partir de $1^{\circ}$ de janeiro de 2016 (ONU, 2015).

No que diz respeito à Educação Superior (ES), em especial nos países do continente latino-americano, a Agenda 2030 demanda significativa mudança de postura, dado suas instituições terem sido, historicamente, elitistas e excludentes, quase indiferentes à desigualdade estrutural do continente e à quantidade de grupos e pessoas em situação de vulnerabilidade (Quijano, 2005). Nas décadas 
recentes, porém, associações acadêmicas e as Conferências Regionais de Educação Superior (CRES), como a recém realizada em Córdoba (2018), tem deixado claro outro posicionamento, em defesa da ES como bem público e direito social (Meneghel et al., 2018). Ou seja: sem a redução de desigualdades no âmbito dos governos, mas também das próprias instituições, a ES não atuará potencializando a justiça social, a equidade e o desenvolvimento sustentável.

Nessa linha, é significativo observar o caso do Brasil, um dos países mais desiguais do mundo. Conforme estudo publicado pelo IPC-IG/PNUD(1) que analisou 29 países (entre desenvolvidos e em desenvolvimento), ele está entre as cinco nações em que a parcela mais rica da população recebe mais de $15 \%$ da renda nacional. O 1\% mais rico do Brasil concentra entre $22 \%$ e $23 \%$ do total da renda do país, nível muito mais elevado que a média internacional. Com uma população de pouco mais de 200 milhões de habitantes (IBGE, 28 ago. 2019), suas matrículas na ES correspondem a cerca de 50\% do total da América Latina (Souza, 2018), indicando o forte impacto que as instituições acadêmicas podem ter sobre a região.

Importa observar que, a despeito de ser uma das últimas nações do continente a contar com Instituições de Educação Superior (IES)(2), a partir de meados no século XX o Brasil conseguiu desenvolver um sistema educacional robusto, inclusive em termos de pós-graduação. E, embora tenha se constituído e consolidado como um espaço a serviço da reprodução da elite e da desigualdade (Wittkowski, \& Meneghel, 2019), há pouco mais de uma década passou a implantar políticas de ação afirmativa (PAA) com o objetivo de promover alterações neste quadro.

Em face do exposto, este artigo objetiva analisar três indicadores da ES brasileira, a fim de identificar sua possibilidade de contribuir com a Agenda 2030; aborda, em específico, os relacionados com: assegurar educação inclusiva e equitativa

(1) O Centro Internacional de Políticas para o Crescimento Inclusivo vinculado ao Programa das Nações Unidas para o Desenvolvimento (IPC-IG/PNUD) realiza estudos e conhecimentos voltados às políticas públicas e intercâmbio de boas práticas de cooperação Sul-Sul e desenvolvimento. (Souza, \& Medeiros, 2017).

(2) A criação de faculdades era absolutamente proibida e tornou-se possível no Brasil apenas em 1808, quando a Família Real Portuguesa se instalou no Rio de Janeiro. (Trindade, 2000). 
de qualidade; promover o crescimento econômico, inclusivo e sustentável, emprego pleno e trabalho para todos; e reduzir a desigualdade interna.

A escolha de indicadores para o estudo atendeu ao observado em pesquisas similares realizadas na América Latina. Neste sentido, observamos ser comum a utilização de dados de gênero; no entanto, eles não são relevantes no Brasil, uma vez que desde meados de 1970 há mais mulheres que homens na ES como ingressantes e concluintes (Beltrão, \& Alves, 2009). Do mesmo modo, são frequentes pesquisas com o nível de escolaridade dos pais e local de conclusão do ensino médio (público ou privado), dado que filhos de famílias com baixo capital cultural e social têm maior dificuldade para chegar às universidades (Fanelli, 2014). Neste sentido, as universidades públicas brasileiras, em particular as federais, tem mostrado melhoras significativas nestes números após a instalação de políticas de cotas - como mostra, em detalhe, estudo elaborado pela Associação Nacional de Dirigentes das Instituições Federais de Ensino Superior (FONAPRACE, 2019).

Diante do exposto, tomamos como indicadores de democratização:

(i) acesso da população baixa renda;

(ii) diversidade racial;

(iii) acesso de estudantes com deficiência.

A escolha do primeiro deve-se a Relatório da CINDA (2017), que mostra como, em todo o continente latino-americano, a renda familiar é determinante no acesso à educação. Ele indica, ainda, o papel determinante da ES na redução da desigualdade social e promoção de desenvolvimento humano. Também podemos observar, em diversos países latino-americanos, forte vínculo entre baixa renda, racismo com relação a indígenas e afrodescendentes, e acesso à ES conforme apresentam os estudos publicados na Revista Universidades, da UDUAL, que dedicou um dossiê ao tema ${ }^{(3)}$. No caso específico do Brasil, Silva (2021) revela que apesar de 55,4\% da população ser negra ou parda, este grupo compõem a maior parte da população de analfabetos do país, assim como eles são o segmento mais prejudicado quando analisados todos os demais níveis de escolarização do país - da educação infantil à superior. A autora mostra ainda

(3) Ver vol. 72 Núm. 87 (2021): Racismo y educación superior en América Latina. 
que, quando comparados a brancos, negros e pardos dispõem de piores condições de renda e moradia, e são submetidos a maiores índices de violência. Desta forma justificamos a escolha do segundo indicador.

Finalmente, analisamos o acesso de estudantes com deficiência à ES, dada a pequena produção de estudos sobre o tema no país e na região latino-americana, em particular, estudos de larga escala. Em geral, eles se dedicam a mostrar que este grupo, além de baixa representatividade nas IES, tem maiores dificuldades de acesso e permanência, assim como de participação em quase todas as atividades acadêmicas (Chiroleu, 2009; Calduch et ali, 2017).

A metodologia deste estudo foi fundamentada na pesquisa bibliográfica e documental(4), tomando como fontes de consulta: a legislação brasileira referente aos processos de inclusão na ES, as diretrizes internacionais para a ES (em especial os documentos das Conferências Regionais de ES de 1996, 2008 e 2018 e das Conferências Mundiais de 1998 e 2009) e dados e estatísticas de institutos de pesquisa(5).

Esta reflexão visa contribuir para o debate acerca dos avanços e desafios da ES brasileira no âmbito da Agenda 2030 e, também, para a importância das políticas públicas de ES nos países latino-americanos, com vistas à promoção da inclusão, da diversidade e do desenvolvimento econômico e social no continente.

\section{Os Objetivos da Agenda 2030 e a Educação Superior Brasileira}

As IES, e especialmente as Universidades, são parte da história recente do Brasil. Somente após a $2^{a}$ grande guerra mundial houve, por parte do Estado, interesse na criação destas instituições em todo o seu território, assim como a criação de agências de fomento à pesquisa. No período da Ditadura Militar

\footnotetext{
${ }^{(4)}$ Neste texto, análise documental é compreendida como: "atividade de localização e consulta de fontes diversas de informação escrita, orientada pelo objetivo explícito de coletar materiais mais genéricos ou mais específicos a respeito de um tema" (LIMA, 2008, p. 48).

(5) Foram eles: (i) Instituto Brasileiro de Geografia e Estatística (IBGE), responsável pelo Estudo das Desigualdades por Cor ou Raça e pela Pesquisa Nacional por Domicílios Contínua (PNAD), além dos dados do Censo Demográfico 2010; (ii) Instituto Nacional de Estudos e Pesquisas Educacionais Anísio Teixeira (INEP) vinculado ao Ministério da Educação (MEC), responsável pelos dados do Censo da Educação Superior (2019).
} 
(1964-1985), em que pese ter havido a modernização da estrutura acadêmica e institucional de universidades do setor público, bem como a criação da pósgraduação e o estímulo à produção de conhecimento, também teve início a privatização do sistema (Trindade, 2000).

Em meados da década de 1990, após um largo período de recessão econômica, com queda de recursos públicos para pesquisa e manutenção das instituições em função da influência do Banco Mundial, a política para o setor passou por novo período de expansão; desta vez, porém, beneficiada pela criação de um arcabouço legislativo de apoio à criação de IES privado-mercantis, ou seja, com fins lucrativos. Como resultado, assim como em outros países latino-americanos, houve diversificação dos tipos de instituição e modalidades de ensino, que gerou rápida expansão da educação a distância e de cursos tecnológicos, de menor duração. Este fato, aliado à oferta de cursos de baixo custo e com exigências acadêmicas menores, tanto para o ingresso como para o prosseguimento dos estudos, permitiu a absorção da enorme demanda de estudantes com interesse em fazer um curso superior (Sguissardi, 2015; Fanelli, 2017).

Importante também observar que, a partir de 2005, por estímulo de governos progressistas, houve forte expansão do setor público, que duplicou o número de instituições e matrículas em pouco mais de uma década. Ainda assim, seu crescimento ficou muito aquém do privado, que seguiu absorvendo a maior parte da demanda por ES (INEP, 2019), conforme revela o gráfico 1.

Gráfico 1. Censo da Educação Superior 2018: Notas Estatísticas (2019)

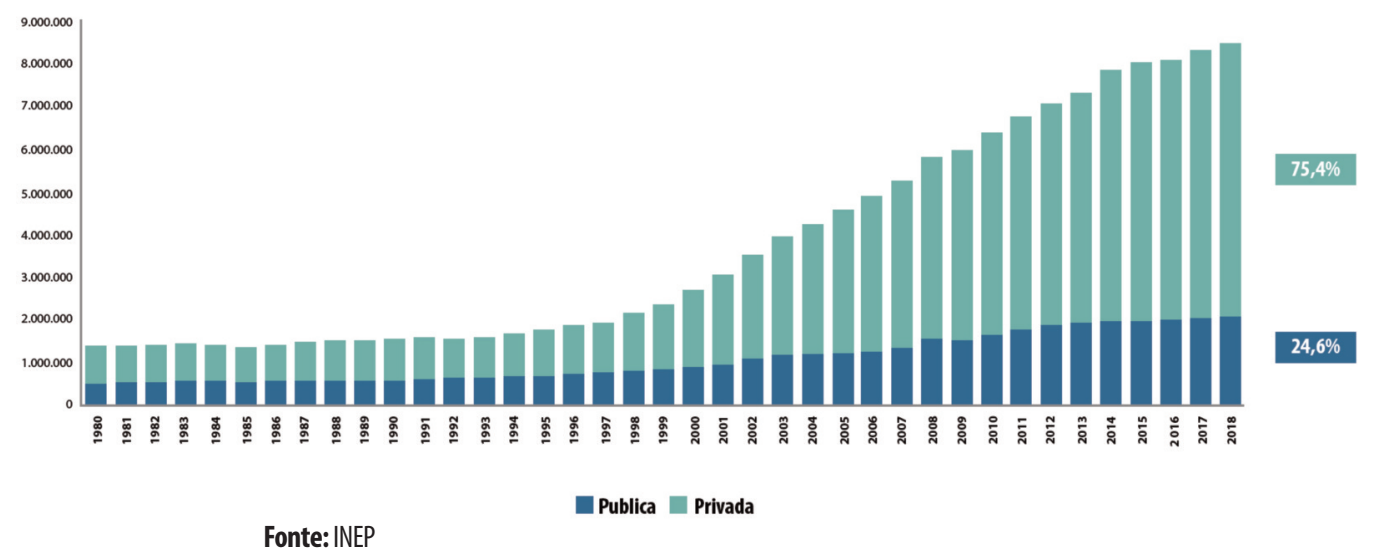


O número de matrículas dos cursos de graduação teve, entre 2008 e 2018, crescimento anual médio de $3,8 \%$, o que significou um aumento de $56,4 \%$ no período - dado que aponta para significativa ampliação do acesso à ES. No entanto, em 2018, quando o total de matrículas atingiu 8,4 milhões, cerca de 6,3 milhões dos estudantes frequentaram a rede privada (INEP, 2019); ou seja, três em cada quatro alunos de graduação precisavam pagar mensalidades para se manter na ES. E, como argumentam Martins et al. (2019), se a inclusão ocorre predominantemente via IES privadas, muitas delas com baixa qualidade, é questionável quanto ela é efetiva.

Vale ressaltar que todo este processo de expansão, público e privado, esteve associado à adoção de políticas de ações afirmativas (PAA). Estas políticas, de acordo com o Grupo de Trabalho Interministerial para a Valorização da População Negra no Brasil, têm como objetivo:

[...] eliminar desigualdades historicamente acumuladas, garantindo a igualdade de oportunidades e tratamento, bem como compensar perdas provocadas pela discriminação e marginalização, decorrentes de motivos raciais, étnicos, religiosos, de gênero e outros (Santos, 1999, p.25).

Conforme Wittkowski (2020), as principais PAA desenvolvidas no âmbito das IES públicas foram a Lei 12.711, de 29 de agosto de 2012, conhecida como Lei de Cotas, e o Programa Nacional de Assistência Estudantil (Pnaes). A Lei de Cotas reserva metade (50\%) das vagas das IES para estudantes oriundos de escolas públicas, distribuídas em alguns segmentos: famílias baixa renda, negros, indígenas e pessoas com deficiência. O Pnaes, por sua vez, apoia a permanência de estudantes de baixa renda matriculados em cursos de graduação presencial das instituições públicas; ele prevê, além de benefícios financeiros, apoio pedagógico (Brasil, 2020b). No âmbito das IES privadas, as principais PAA implantadas foram: o Fundo de Financiamento ao Estudante do Ensino Superior (FIES) e o Programa Universidade para Todos (Prouni). O FIES, criado pelo Governo Federal em 1999, concede créditos para o financiamento de cursos superiores presenciais a estudantes com renda familiar de até três salários-mínimos (Brasil, 2020a). A quantidade de recursos investidos no FIES cresceu exponencialmente no governo do Presidente Luiz Ignácio Lula da Silva, que também criou o Prouni, em 2005; 
este programa oferece bolsas de estudos integrais e parciais a estudantes de famílias com baixa renda e que cursaram o ensino médio exclusivamente em escolas públicas (Brasil, 2020c).

Com a implantação das PAA, o elevado crescimento de matrículas incidiu sobre uma camada da população antes excluída de ES, gerando um novo perfil socioeconômico de estudantes de graduação. Conforme Ristoff (2014), entre 2004 e 2012 houve significativa diminuição de estudantes oriundos de famílias de alta renda. No entanto, estes benefícios podem ser efêmeros: tanto as cotas das instituições públicas quanto os fundos e investimentos concedidos pelo Estado têm caráter transitório, dependendo do interesse do Governo Federal para serem mantidos.

A criação das PAA, bem como o significativo aumento de recursos investidos, deu-se no contexto da CRES 2008, que reafirmou a necessidade de governos e instituições se comprometerem com a inclusão social e os objetivos do desenvolvimento sustentável. Também a CMES de 2009 ressaltou a importância de investimentos para que a ES desenvolvesse responsabilidade quanto à diminuição das desigualdades, erradicação da pobreza e realização dos direitos humanos, contribuindo com os objetivos citados (UNESCO, 2009).

Para Nascimento (2012), o conjunto das propostas para o desenvolvimento sustentável tem várias direções: ambiental, econômica e social. A primeira supõe um equilíbrio entre a produção e o consumo, de forma a garantir a capacidade de recuperação dos ecossistemas; a segunda, acredita na ecoeficiência e na constante inovação tecnológica como estratégias de reduzir o consumo de recursos naturais; e a terceira tem, por foco, a necessidade de erradicar a pobreza para estabelecer o padrão aceitável de desigualdade, com a implantação da justiça social.

No âmbito da dimensão social, tem destaque os objetivos educacionais, essenciais ao desenvolvimento sustentável, dado seu potencial transformador humana. Eles não apenas contribuem para a formação de uma nova consciência sobre os direitos humanos, mas também promovem o empoderamento dos sujeitos e sua inclusão social - independente de deficiência, raça, etnia ou condição econômica (ONU, 2015). A educação em nível superior tem papel fundamental em ambos os sentidos: conscientização e empoderamento. Ela pode, por meio da conscientização de estudantes, sensibilizar para a importância e necessidade da sustentabilidade em todas as suas dimensões, além de fomentar 
mudanças de atitudes que impliquem numa sociedade mais democrática, inclusiva e com equidade. Nessa linha, fazer com que os espaços acadêmicos sejam representativos da diversidade social, em convivência pacífica e com objetivos acadêmicos comuns, pode ser determinante para esta nova construção social. Do mesmo modo, como aponta Mazzilli (2011), fazer com que ensino, produção de conhecimento e ações de extensão tenham em vista a Agenda 2030, possibilita às IES realizarem seu compromisso de atender as demandas da população, ao mesmo tempo em que auxiliam na formação de sujeitos sociais.

No que se refere aos Objetivos para o Desenvolvimento Sustentável oriundos da Agenda 2030, há significativa contribuição da formação na ES para o desenvolvimento econômico. Um diploma superior propicia acesso a trabalhos decentes e melhor remunerados; por extensão, apoia a redução das desigualdades e a redução da pobreza. Nesse sentido, diversos estudos, como o da Cinda (2017), apontam a importância da ES no fornecimento de experiências e aprendizagens que conferem aos sujeitos novas e melhores condições de participação no mercado de trabalho, bem como a relação direta entre aumento de escolaridade e índices salariais. Deste modo, a ES pode proporcionar crescimento econômico não só para os indivíduos que a frequentam, mas também para sua família e comunidade.

Mas, para além de colaborar para o desenvolvimento econômico, a ES tem papel fundamental na promoção de respeito às diversidades e inserção de todos os grupos sociais. À medida que o acesso a este nível de formação é compreendido como um bem público e direito social, não é admissível em seus espaços nenhuma forma de preconceito ou discriminação: de raça, cor, etnia, religião, gênero, classe social, deficiência. A convivência respeitosa de diferentes sujeitos dentro dos seus muros é fundamental para a construção de uma sociedade menos desigual e excludente (Quijano, 2005).

Nesse sentido, vale observar o ODS 4, que visa "assegurar a educação inclusiva e equitativa de qualidade e promover oportunidades de aprendizagem ao longo da vida para todos" (ONU, 2015). Esta meta tem diversos desdobramentos em termos dos grupos populacionais e, também, no que tange à permanência $\mathrm{e}$ êxito da formação, conforme destaca o documento do Instituto de Pesquisa Econômica Aplicada (IPEA, 2019): 
Meta 4.5 (Brasil) - Até 2030, eliminar as desigualdades de gênero e raça na educação e garantir a equidade de acesso, permanência e êxito em todos os níveis, etapas e modalidades de ensino para os grupos em situação de vulnerabilidade, sobretudo as pessoas com deficiência, populações do campo, populações itinerantes, comunidades indígenas e tradicionais, adolescentes e jovens em cumprimento de medidas socioeducativas e população em situação de rua ou em privação de liberdade (p. 15).

Estas recomendações são enormes desafios para o Brasil posto que, ainda conforme o IPEA (2019), a desigualdade na ES do país atinge especialmente "os negros, os pertencentes ao quarto mais pobre da população e os moradores rurais e das regiões Norte e Nordeste" (p.16) e a formação deve ser de qualidade, além de gratuita ou a preços acessíveis.

Atentos a este contexto, analisamos como se comportaram, na última década, indicadores de ES no Brasil relativos ao acesso: da população com baixa renda; da diversidade racial e de pessoas com deficiência. Buscaremos identificar como, no cenário da expansão, as PAA interferiram na sua inclusão e alcance das metas da ODS.

\section{Acesso da população baixa renda}

De acordo com os dados do PNAD (2017), estima-se que dos 207,1 milhões de pessoas residentes no Brasil, 124,6 milhões (60,2\%) possuam algum tipo de renda - seja proveniente de trabalho $(41,9 \%)$ ou de outras fontes $(24,1 \%)$, como aposentadoria, aluguel e programas de transferência de renda. $\mathrm{E}$, dentre os que declararam possuir algum rendimento, este foi estimado no valor médio de $\mathrm{R} \$$ $2.112,00$ ao mês(6). Em realidade, porém, a distribuição deste valor no conjunto da população é bastante desigual: os $50 \%$ da população com menores rendimentos recebem, em média, $R \$ 754,00$ mensais, enquanto $1 \%$ da população com maior renda ganha, em média, R\$ $27.213,00$ por mês - ou seja, 36,1 vezes mais que metade da população.

(6) Ou seja, este seria o ganho médio, no Brasil, de cada pessoa que declara ter alguma renda, caso todos recebessem o mesmo valor mensal. 
$\mathrm{O}$ acesso à ES reflete a desigualdade do país. Indicadores socioeconômicos mostram que, em geral, estudantes cujos pais têm escolaridade superior, possuem uma renda familiar mais elevada; eles também frequentam cursos predominantemente elitizados (como Medicina e Arquitetura), com altos percentuais de pessoas brancas e oriundas da escola do ensino médio privado. Na outra ponta, estudantes cujos pais não têm escolaridade superior demonstram ter famílias com menor rendimento; eles estudam em cursos com mais baixos percentuais de brancos (ou seja, mais próximos à realidade brasileira) e têm origem escolar na educação pública (Ristoff, 2014).

Mas, como apontado na seção anterior, em função da implantação de PAA na ES - tanto em instituições públicas quanto privadas - este quadro vem sendo significativamente alterado. No que refere especificamente aos matriculados nas instituições federais de ES, dados constantes da $V$ Pesquisa do Perfil Socioeconômico e Cultural dos Estudantes de Graduação das Instituições Federais De Ensino Superior Brasileiras (Fonaprace, 2018) apontam que 53,5\% dos graduandos das instituições federais de ES têm renda mensal familiar per capita na faixa de "Até 1 salário mínimo - (SM)", e 70,2\% tem renda mensal familiar per capita de "Até 1 e meio salário mínimo (SM)"(.)

No período de 1996 a 2018, o percentual de estudantes de famílias com renda mensal per capita "Até 1 e meio SM" passou de 44,3\%, em 1996, para 66,2\% em 2014, alcançando 70,2\% em 2018 - maior patamar da série histórica (Fonaprace, 2018). Estes índices são bastante expressivos de uma reversão no antigo cenário de elitização das IES públicas, consideradas de maior qualidade e, portanto, de mais difícil acesso a estudantes de famílias com baixa renda.

Considerado o exposto, fica clara a efetividade das PAA no que tange ao acesso de estudantes de famílias baixa renda à ES gratuita e de qualidade. Contudo, é significativo que, nos dados relativos à permanência, o mesmo relatório revele que dentre o total de discentes que pensam em abandonar o curso, 32,7\% apontem como causa dificuldades financeiras e, ainda, que $23,6 \%$ indiquem não conseguir conciliar seu trabalho, única fonte de sustento, com os estudos (Fonaprace, 2018). Para a população baixa renda, após o acesso à ES por meio das PAA, existe outro enorme desafio: o da permanência.

(7) Tomamos como referência do salário mínimo o valor praticado de 01/01/2018 a 31/12/2018: $\mathrm{R} \$ 954,00$ (novecentos e cinquenta e quatro reais). 


\section{Diversidade Racial}

Estudo recente, intitulado Desigualdades Sociais por Cor ou Raça no Brasil (IBGE, 2019), descreve as desigualdades entre brancos e pretos ou pardos no que se refere ao trabalho, à moradia, à educação, à distribuição de renda, à violência e à representação política. Conforme os dados, a população brasileira tinha, em 2018 , a seguinte configuração: $46,5 \%$ era parda; $9,3 \%$, preta; e $43,1 \%$ branca. Esses três grupos, juntos, representavam $99 \%$ do total de moradores do país; indígenas e amarelos representavam $1 \%$.

De acordo com Mário Theodoro"a desigualdade racial, antes de ser o problema em si, é o resultado de processos diversos, nos quais o racismo e seus desdobramentos, o preconceito e a discriminação, destacam-se como fontes primárias" (2008, p.171). Ainda segundo o autor, o racismo vivenciado no Brasil parte da ideologia de superioridade de determinados grupos sobre outros, fundamentando-se nas diferenças raciais. Isso justificaria a discriminação racial e a reprodução do preconceito no dia a dia, por meio de predisposições negativas diante de pessoas negras. Diante desse fenômeno, tem-se apontado a necessidade de incentivar a adoção de políticas afirmativas, com vistas a quebrar estereótipos e combater visões que alimentam o tratamento excludente e a desigualdade(8).

Mas o debate sobre a implementação de políticas de ações afirmativas no âmbito da ES brasileira não é recente. Segundo Jaccoud (2008), ele remete à década de 1930, quando o Movimento Negro já afirmava a necessidade de a população negra ter a garantia do acesso à educação. No entanto, as primeiras experiências foram vivenciadas somente no final de 1990, com a criação de cursinhos universitários pré-vestibulares voltados a estudantes negros, ligados à lgreja Católica e a setores da sociedade civil.

Em 2001 foram criados os primeiros PAA em universidades públicas com foco na população negra. Desenvolvidas de forma voluntária e autônoma, respon-

\footnotetext{
(8) No Brasil, avanços no reconhecimento da existência da desigualdade racial como um problema do país tiveram início no governo do presidente Fernando Henrique Cardoso, após a criação do Grupo de Trabalho Interministerial pela Valorização da População Negra (GTI), em 1995. No governo do presidente Lula da Silva, por sua vez, houve a criação da Secretaria Especial de Políticas de Promoção da Igualdade Racial (Seppir), em 2003, responsável pela formulação de políticas e ações de enfrentamento da temática.
} 
dendo a deliberações dos conselhos universitários e implantados via adoção de sistemas de cotas ou bonificações, esses programas atuaram como uma estratégia de ampliação da participação dos negros em um espaço social onde sua presença era extremamente restrita (Jaccoud, 2008).

Estas ações ganharam outra densidade a partir da aprovação do Estatuto da Igualdade Racial(9) e das Leis 12.711/2012 e 12.990/2014 que, respectivamente, criaram uma política de cotas para toda a rede federal de ensino (técnico, médio e superior) e para o serviço público federal (Brasil, 2018). Como resultado, as cotas para negros representavam, em 2015, 31\% das vagas oferecidas pela rede federal de ES - fração que, até aquele momento, não havia atingido nenhum outro segmento populacional. E, no âmbito das IES Federais, em 2018 as cotas se aproximavam de $50 \%$ das vagas, tendo com isso provocado grande mudança no perfil dos estudantes quanto à cor e raça: $51,2 \%$ eram negros ou pardos, 43,3\% brancos; $2 \%$ amarelos e 0,9\% indígenas (Fonaprace, 2018).

É possível perceber que a experiência brasileira de promoção da igualdade racial na ES por meio de cotas está se afirmando, como aponta Jaccoud (2008, p. 163).

A iniciativa de adotar um tratamento preferencial em benefício dos estudantes negros tem mostrado resultados positivos, como apontam os dados e ampliado as possibilidades de diversificação da elite profissional brasileira nos diferentes campos do conhecimento e da atuação profissional. Seu impacto tende a ser crescente ao longo do tempo, inclusive afetando a trajetória dos alunos brancos, que passam a ser influenciados por uma experiência de maior diversidade no ambiente universitário.

Também é importante destacar que, nos anos recentes, a ação pública brasileira tem expandido o espectro de PAA, promovendo um conjunto diversificado de ações que, inovadoras no campo do enfrentamento ao racismo institucional, estão aliadas à legislação antirracista e a esforços no sentido do reconhecimento

\footnotetext{
(9) Trata-se da Lei 12288/2010, que visa garantir à população negra a efetivação da igualdade de oportunidades, a defesa dos direitos étnicos individuais, coletivos e difusos e o combate à discriminação e às demais formas de intolerância étnica (Oliveira, 2013).
} 
de direitos coletivos. Ambas as frentes constituem uma teia de possibilidades políticas de combate à desigualdade racial.

No entanto, ainda há muito por fazer. A escolaridade dos pretos e pardos no Brasil tem melhorado, mas permanece abaixo do índice dos brancos, em especial no que refere à ES. Entre os jovens de 18 a 24 anos (faixa considerada adequada a esse nível de formação), entre os que se declaram pretos ou pardos a proporção dos que frequentam algum curso superior é de $55,6 \%$ - patamar bem abaixo dos $78,8 \%$ de estudantes brancos da mesma faixa etária. E embora pretos e pardos tenham passado a compor a maioria nas IES da rede pública federal (50,3\%), eles ainda seguem sub representados, dados que perfazem $55,9 \%$ da população total do país. (IBGE, 2019).

Dentre os jovens de 18 a 24 anos que frequentam ou não alguma instituição de ensino, a porcentagem dos matriculados ou que já havia concluído a ES foi de $36,1 \%$ entre brancos, enquanto foi de $18,3 \%$ entre pretos ou pardos. Também a taxa de ingresso na ES (independe de conclusão) dos pretos ou pardos foi de $35,4 \%$; entre brancos, $53,2 \%{ }^{(10)}$

Diante do exposto, embora seja visível a diminuição de indicadores de desigualdade racial na ES, diferenças socioeconômicas entre pretos ou pardos e brancos e racismo ainda persistem no Brasil, como revela o Quadro 1.

Os dados não permitem omitir a existência das desigualdades raciais, bem como a complexidade deste fenômeno, um desafio para governos e para a sociedade em geral. Mas, como afirmam Bertolin, Amaral e Almeida (2019), a origem social e a situação econômica familiar dos estudantes são determinantes na trajetória do jovem pela ES; por isso se faz tão importante que políticas públicas de inclusão priorizem estes grupos.

\footnotetext{
(10) O relatório IBGE (2019) mostra como esta desigualdade é estrutural desde a conclusão do ensino médio. O percentual de pessoas de 20-22 anos que concluíram esse nível de ensino na população preta ou parda era de $61,8 \%$; entre brancos, $76,8 \%$. E entre o total de jovens brasileiros de 18 a 24 anos com ensino médio completo que não estavam frequentando alguma IES por terem que trabalhar ou procurar trabalho, $61,8 \%$ eram pretos ou pardos.
} 


\section{Quadro 1: Desigualdades Sociais por Cor ou Raça no Brasil}

\begin{tabular}{l|l}
\hline ANALFABETISMO & $\begin{array}{l}\text { A taxa de analfabetismo é muito maior entre pretos e pardos } \\
(9,1 \%) \text { do que entre brancos }(3,9 \%) .\end{array}$ \\
\hline MERCADO DE TRABALHO & $\begin{array}{l}\text { Cerca de } 64 \% \text { dos desempregados são pretos ou pardos. } \\
\text { Independente do nível de instrução, pretos e pardos recebem } \\
\text { menos que brancos. Brancos com ES completo ganhavam } 45 \% \text { a } \\
\text { mais do que os pretos ou pardos com o mesmo nível de instrução. }\end{array}$ \\
\hline $\begin{array}{l}\text { Somente } 29,9 \% \text { dos cargos gerenciais são exercidos por pretos ou } \\
\text { pardos. }\end{array}$ \\
\hline DISTRIBUIÇÃO DE RENDA & $\begin{array}{l}\text { Pretos ou pardos representam 75,2\% do grupo formado pelos } \\
10 \% \text { da população com os menores rendimentos. }\end{array}$ \\
\hline CONDIÇÕES DE MORADIA & $\begin{array}{l}44,5 \% \text { dos pretos ou pardos vivem em domicílios onde falta ao } \\
\text { menos um serviço de saneamento básico. }\end{array}$ \\
\hline VIOLÊNCIA & $\begin{array}{l}\text { Pretos ou pardos têm 2,7 vezes mais chances de ser vítima de ho- } \\
\text { micídio do que brancos. }\end{array}$ \\
\hline REPRESENTAÇÃO POLÍTICA & $\begin{array}{l}\text { Apenas } 24,4 \% \text { dos deputados federais, 28,9\% dos deputados es- } \\
\text { taduais e 42,1\% dos vereadores eleitos são pretos ou pardos. }\end{array}$ \\
\hline
\end{tabular}

Fonte: IBGE, Desigualdades Sociais por Cor ou Raça no Brasil, 2019.

\section{Acesso do estudante com deficiência}

De acordo com orientações internacionais, são consideradas pessoas com deficiência os indivíduos que afirmam ter muita dificuldade em uma ou mais das seguintes habilidades: visual, auditiva, intelectual e motora. No Brasil, segundo o Censo (2010), cerca de 46 milhões de brasileiros, ou seja, 24\% da população, tem algum grau de dificuldade em ao menos uma das referidas habilidades. $\mathrm{E}$ mais de 12,5 milhões de brasileiros, o que corresponde a $6,7 \%$ do total, tem efetivamente uma deficiência - ou seja, possuem grande ou total dificuldade para enxergar, ouvir, caminhar ou subir degraus, além dos que declararam ter deficiência mental ou intelectual. 
Após a Lei de Cotas, outro avanço extremamente significativo para a inclusão de pessoas com deficiência na ES foi a Lei Brasileira de Inclusão (Lei 13.146/2015), que passou a garantir que qualquer pessoa, com ou sem deficiência, possa ter acesso a um lugar, serviço, produto ou informação de maneira segura e autônoma, sem nenhum tipo de barreira. No que tange à oferta de educação, o artigo 28 da Lei estabelece as obrigações do poder público em relação à pessoa com deficiência, compreendendo as instituições de ensino público e privado, de qualquer nível ou modalidade.

Art. 28. Incumbe ao poder público assegurar, criar, desenvolver, implementar, incentivar, acompanhar e avaliar:

I- sistema educacional inclusivo em todos os níveis e modalidades, bem como o aprendizado ao longo de toda a vida;

II - aprimoramento dos sistemas educacionais, visando a garantir condições de acesso, permanência, participação e aprendizagem, por meio da oferta de serviços e de recursos de acessibilidade que eliminem as barreiras e promovam a inclusão plena [...]

V-adoção de medidas individualizadas e coletivas em ambientes que maximizem o desenvolvimento acadêmico e social dos estudantes com deficiência [...]

XIII - acesso à Educação Superior e à educação profissional e tecnológica em igualdade de oportunidades e condições com as demais pessoas (Brasil, 2015).

Embora a inclusão de pessoas com deficiência esteja legalmente estabelecida, no âmbito educacional, ainda se encontram inúmeros desafios à sua inclusão, principalmente nos níveis mais avançados de ensino. Poucos conseguem concluir os estágios anteriores de formação (educação básica) até chegar à ES e, menor ainda, é o índice dos que concluem a graduação. Diante destas considerações, podemos compreender o quantitativo de pessoas com deficiência nas instituições de ES brasileiras, indicados na tabela 1, referentes ao ano 2018.

Conforme o Censo (2010), nos últimos dez anos houve significativo aumento de matrículas de pessoas com deficiência na ES: elas mais que dobraram entre 2009 e 2018, passando de 20.530 para 43.633 matriculados. No entanto, se considerado este percentual em relação ao total de estudantes em cursos de gra- 


\section{Tabela 1. Pessoas com deficiência nas instituições de ES brasileiras}

\begin{tabular}{|c|c|c|}
\hline Ano & $\begin{array}{l}\text { Número de matrículas de alunos } \\
\text { con deficiência, trastornos globais } \\
\text { do desenvolvimento ou altas } \\
\text { habilidades/superdotaçăo }\end{array}$ & $\begin{array}{l}\text { Percentual en relação } \\
\text { a total de matrículas } \\
\text { en cursos de graduaçäo }\end{array}$ \\
\hline 2009 & 20.530 & $0,34 \%$ \\
\hline 2010 & 19.869 & $0,31 \%$ \\
\hline 2011 & 22.455 & $0,33 \%$ \\
\hline 2012 & 26.663 & $0,38 \%$ \\
\hline 2013 & 29.221 & $0,40 \%$ \\
\hline 2014 & 33.475 & $0,43 \%$ \\
\hline 2015 & 37.986 & $0.47 \%$ \\
\hline 2016 & 35.891 & $0,45 \%$ \\
\hline 2017 & 38.272 & $0,46 \%$ \\
\hline 2018 & 43.633 & $0,52 \%$ \\
\hline
\end{tabular}

Fonte: INEP, Censo da Educação Superior, 2018: Notas Estatísticas (2019)

duação em 2018, as pessoas com deficiência representam apenas 0,52\% do total. E, tendo em conta que elas compõem $6,7 \%$ da população brasileira, fica perceptível quanto este grupo segue sub representado.

De acordo com Brizolla e Martins (2018), o aumento no número de matrículas pode ser atribuído às PAA que, como vimos, passaram a garantir cotas de acesso à ES para as pessoas com deficiência. No entanto, tal como no caso dos estudantes de baixa renda, o acesso é apenas o primeiro desafio. Anache e Cavalcante (2018) afirmam que a evasão entre os estudantes com deficiência é de $27 \%$ nas IES da rede púbica, sendo ainda maior na rede privada: $31,5 \%$.

A permanência destes sujeitos na ES depende fortemente de políticas de apoio pedagógico desenvolvidas pelas instituições; estas assumem a maior importância na efetivação da garantia de sucesso escolar pois, do contrário, a inserção de pessoas com deficiência nas atividades de desenvolvimento acadê- 
mico fica limitada ou impossibilitada. No caso do Brasil, segundo Brizolla e Martins (2018), as IES ainda são incipientes na incorporação de políticas de inclusão e permanência dos estudantes com deficiência, tendendo a prover serviços e recursos de forma pontual, segundo demandas e necessidades individuais. Este fato tende a deslocar o debate da inclusão na ES, como fenômeno macro, para questões mais simples, relativas à capacidade e interessa das IES na implantação de técnicas e recursos assistivos ${ }^{(11)}$.

De toda forma, a educação inclusiva deve contribuir para transformações tanto na instituição acadêmica quanto nos estudantes, que precisam aprender a acoIher a diversidade e as diferenças com vistas a garantir, conforme a meta 4.5 (Brasil) dos ODS: "a equidade de acesso, permanência e êxito em todos os níveis, etapas e modalidades de ensino para os grupos em situação de vulnerabilidade, sobretudo as pessoas com deficiência" (IPEA, 2019, p. 15).

Os análise das datas em que as PAA foram implantadas indica que os avanços em termos de inclusão das diversidades foram obtidos essencialmente nos mandatos dos Presidentes Luiz Inácio Lula da Silva e Dilma Rouseff, cujos governos foram marcados pelo combate à pobreza e as desigualdades sociais. Contudo, o Brasil ainda está distante do cumprimento pleno das metas estabelecidas pela ONU. Segundo o Relatório-Luz do Grupo de Trabalho da Sociedade Civil para Agenda 2030:

Os resultados são extremamente preocupantes diante dos desafios de erradicar a pobreza e eliminar a fome, assegurar a inclusão socioprodutiva, garantir uma vida saudável, alcançar a equidade de gênero, construir infraestrutura resiliente e acessível a todas as pessoas, promover industrialização inclusiva e sustentável, estimular a inovação e proteger os ecossistemas marinhos (Nilo; Almeida Pinto, 2017, p. 2).

(11) Diante disso, para Brizolla; Martins (2018) o debate sobre inclusão educacional, institucional e universitária de estudantes com deficiência implica questionar o plano políticopedagógico da universidade e sua abertura para lidar com as diversidades - tal como ocorre nas escolas de educação básica. 
Também importa observar que, nos últimos quatro anos, o país tem retrocedido em conquistas fundamentais, imerso em uma crise política sem precedentes, "onde forças conservadoras ganham espaço nos poderes Executivo e Legislativo, impondo os interesses privados e setoriais, tais como as bancadas religiosas, de fabricantes de armas e munições e de ruralistas" (Nilo, \& Almeida Pinto, 2017, p. 3). O processo de inclusão na ES, iniciado pela expansão de vagas e pelas PAA, vem sendo seriamente ameaçado por políticas que vai na contramão das PAA e dos Objetivos de Desenvolvimento Sustentável.

É preciso ter claro, porém, que o enfraquecimento de conquistas sociais no âmbito da ES brasileira, no que refere à inclusão de negros, pobres, indígenas e pessoas com deficiência, não agrava apenas a vulnerabilidade destas populações, mas afeta a sociedade como um todo. Conforme a Agenda 2030, o desenvolvimento sustentável demanda medidas eficazes para remover os obstáculos e empoderar pessoas e grupos fragilizados (IPEA, 2019). O desenvolvimento social depende da melhoria de todos os grupos e segmentos que a compõe.

\section{CONSIDERAÇÕES FINAIS}

O fenômeno da mercadorização da ES pode ser observado em toda a América Latina como parte de iniciativas de 'adequação' dos países às diretrizes de organismos internacionais que atuam em benefício de grandes empresas. Não obstante, ele permitiu o ingresso de uma população anteriormente excluída, de capital econômico e social diverso. Estes novos grupos sociais têm permitido às IES da região atuarem em outra direção, contribuindo para o desenvolvimento econômico e social sustentável - conforme apontam os ODM (2000-2015) e a Agenda 2030). Do mesmo modo, o consenso mundial estabelecido na CMES de 1998, que definiu a ES como um bem público e direito social, explicitado na CMES de $2009^{(12)}$ e reiterado na CRES de Córdoba (2018), chama à responsabilidade das IES para, por meio da inclusão de diversidades, reduzir desigualdades, contribuir para a erradicação da pobreza e construir novos parâmetros de sociedade.

${ }^{(12)} \mathrm{O}$ documento As Novas Dinâmicas do Ensino Superior e Pesquisas para a Mudança e o Desenvolvimento Social reconhece a necessidade de investimento nas instituições de ES com vistas à promoção do desenvolvimento sustentável ambiental, econômico e social. 
Avançar nesta direção de mais justiça, equidade, solidariedade se constitui um desafio para todos os países do mundo, mas especialmente para os da América Latina, cujo processo colonizador estabeleceu uma estrutura social que não apenas reproduz como naturaliza a desigualdade e a exclusão. É fundamental, portanto, que os atores acadêmicos reflitam sobre como atuar no sentido de provocar a abertura das IES da região para a diversidade e a inclusão.

As diretrizes internacionais têm sido determinantes na orientação de políticas governamentais as quais, por sua vez, definem as normas e legislação dos países, direcionando a aplicação de recursos e assegurando direitos. O caso do Brasil, como apresentado neste artigo, é bastante ilustrativo de como os princípios estabelecidos pelas CRES e ratificados pelos ODS foram importantes para que governos progressistas instalassem uma sequência de políticas afirmativas para a ES, propulsoras de mudanças no perfil socioeconômico dos estudantes.

As instituições de ES, precisam ser capazes de atuar como instâncias de formação para uma cidadania efetiva, fomentando a diversidade e a inclusão em perspectiva humanizante e humanizadora. Isso implica modificar as relações existentes, abrindo espaço para novos grupos e pessoas, que antes estavam à margem, e estimulando que jovens de distintos contextos e vivências acadêmicas adquiram percepção da relevância e pertinência dos conhecimentos articulados à realidade social.

E cabe aos governos dos países latino-americanos, por sua vez, bem como à sociedade que mantém instituições de ES de caráter público, empreenderem esforços no sentido de que suas políticas vão além de alimentar expectativas individuais sobre o diploma; elas devem seguir provocando as IES a reverem suas estruturas de acesso e permanência de estudantes, bem como as políticas curriculares e possibilidades de trajetórias de formação.

Neste sentido, as ações afirmativas no Brasil são representativas de como um conjunto de políticas - diretrizes internacionais, legislação nacional e políticas institucionais - pode transformar a realidade dos países. A Lei das Cotas se mostrou bastante eficaz na inclusão de estudantes de grupos sociais historicamente excluídos - além de pessoas com deficiência, os pretos, pardos, baixa renda. As universidades públicas avançaram em percentuais étnico-raciais mais próximos do geral da população brasileira; no entanto, pardos e pretos ainda estão sub representados. Mas os progressos realizados podem ser revertidos, caso ela não seja reeditada - seus benefícios devem ser finalizados em 2022. 
Do mesmo modo, a Lei Brasileira de Inclusão da Pessoa Com Deficiência, aliada a outras alterações da legislação(13) e à Lei de Cotas, foi uma grande conquista para as pessoas com deficiência e a sociedade. Porém, muitas barreiras ainda se impõem à permanência das pessoas com deficiência no âmbito das instituições, pois carecem suporte de políticas macro que assegurem a aprendizagem com vistas à educação para todos.

Os indicadores expostos as PAA geraram sintonia entre as políticas de ES brasileiras e as diretrizes dos ODS, contribuindo para a redução de desigualdades educacionais. Neste sentido, é fundamental renovar esforços para o seu aperfeiçoamento e continuidade. O compromisso de manter leis e estratégias que assegurem o ingresso e sucesso de estudantes pela ES é fundamental para que os avanços já obtidos possam seguir repercutindo na sociedade. Que a observância dos ODS sejam inspiração para que instituições e governos de todos os países da América Latina ampliem sua responsabilidade social e promovam experiências de formação, capazes de reduzir desigualdades, promover equidade e provocar nos jovens reflexão sobre a realidade social e econômica da região

\section{REFERÊNCIAS}

Ancha, Aa., \& Cavalcante LD. (2018). Análise das Condições de Permanência do Estudante com Deficiência na Educação Superior. Psicologia Escolar e Educacional, São Paulo, n. especial, p. 115-125. DOI http://dx.doi.org/10.1590/2175-3539/2018/042

Beltrão, Ki. \& Alves, Jed. (2009). A reversão do hiato de gênero na educação brasileira no século XX. Revista Cadernos de Pesquisa, [s.l.], v.39, n. 136, pp.125-156, jan./abr.

Bertolin, J.; Amaral, A., \& Almeida L. (2019). Os cursos de graduação podem compensar a falta de capital cultural e background de estudantes? Educ. Pesqui., São Paulo, v. 45, e185453. Extraído de https://www.scielo.br/pdf/ep/v45/1517-9702-ep-45-e185453.pdf

${ }^{(13)}$ Como a inserção, nos instrumentos de avaliação e regulação do Estado, de indicadores de adequação da estrutura física das IES às pessoas com deficiência, de obrigatória oferta de profissionais de apoio a estes sujeitos, dentre outros aspectos. 
Brasil. (2012). Lei no 12.711, de 29 de agosto de 2012. Dispõe sobre o ingresso nas universidades federais e nas instituições federais de ensino técnico de nível médio e dá outras providências. Extraído de http://www.planalto.gov.br/CCIVIL_03/_Ato2011-2014/2012/Lei/L12711.htm

Brasil. (2015). Lei n. 13.146, de 6 de julho de 2015. Lei Brasileira de Inclusão da Pessoa com Deficiência. Extraído de http://www.planalto.gov.br/ccivil_03/_Ato20152018/2015/Lei/L13146.htm

Brasil. (2016). Lei n. 13.409, de 28 de dezembro de 2016. Altera a Lei n. 12.711, de 29 de agosto de 2012, para dispor sobre a reserva de vagas para pessoas com deficiência nos cursos técnico de nível médio e superior das instituições federais de ensino. Extraído de http://www.planalto.gov.br/ccivil 03/ ato2015-2018/2016/Lei/L13409.htm

Brasil. (2018). Instituto de Pesquisa Econômica Aplicada - IPEA. Igualdade Racial. Boletim Políticas Sociais: acompanhamento e análise, n. 25.

Brasil. (2019). Instituto Nacional de Estudos e Pesquisas Educacionais Anísio Teixeira - INEP. Censo da Educação Superior 2018: notas estatísticas. Brasília.

Brasil. (2020a). Ministério da Educação. Fundo de Financiamento Estudantil (FIES). Extraído de http://fies.mec.gov.br

Brasil. (2020b). Ministério da Educação. Plano Nacional de Assistência Estudantil (Pnaes). Extraído de http://pnaes.mec.gov.br

Brasil. (2020c). Ministério da Educação. O Programa Universidade para Todos (Prouni). Extraído de http://prouni.mec.gov.br

Brizolla, F., \& Martins, CSL. (2018). Desafios da Educação Inclusiva no Ensino Superior: um retrato das políticas institucionais das universidades federais do sul do Brasil. Revista Triangulo, Uberaba, v.11, n.1, p.136-150, jan./abr. DOI https://doi.org/10.18554/rt.v 0i0.2573.

Carvalho, Pgm. DE, \& Barcellos, FC. (2014). Os Objetivos de Desenvolvimento do Milênio - ODM: Uma avaliação crítica. Sustentabilidade em debate, Brasília, v. 5 n.3, p. 222-244. Extraído de https://periodicos.unb.br/index.php/sust/article/view/ 15662

CINDA (2016), Educación superior en Iberoamérica. Informe 2007. Extraído de: https://cinda.c//wp-content/uploads/2019/01/educacion-superior-en-iberoamerica-informe2016-los-desafios-de-la-educacion-superior-en-el-espacio-iberoamericano.pdf. Acceso en septiembre de 2021 
Chiroleu, A. (2009). La inclusión en la educación superior como política pública: tres experiencias en América Latina Revista Iberoamericana de Educación. n 48/5 - 25 de febrero de 2009. Acceso en: septiembre de 2021.

Fanelli, AG. De. (2014). Inclusión Social en la Educación superior argentina: Indicadores y políticas en torno al acceso y a la graduación. Pág. Educ. [online]. 2014, vol.7, n.2, pp.124-151. ISSN 1688-7468.

FONAPRACE (2019). Fórum Nacional de Pró-Reitores de Assuntos Comunitários e Estudantis Pesquisa Nacional -.V Pesquisa do perfil socioeconômico e cultural dos estudantes de graduação das Instituições Federais de Ensino Superior brasileiras - 2018. Uberlândia: [s. n.], maio de 2019.

IBGE - Instituto Brasileiro de Geografia e Estatística. (2017). Pesquisa Nacional por Amostra de Domicílios Contínua 2017. Rio de Janeiro. n. 311.21:37(81) -E24e, p.12-89. Extraído de https://biblioteca.ibge.gov.br/index.php/biblioteca-catalogo?view=detalhes\&id=2101560

IBGE - Instituto Brasileiro de Geografia e Estatística. (2011). Censo Demográfico 2010: características da população e dos domicílios: resultados do universo. In. Sidra: sistema IBGE de recuperação automática. Rio de Janeiro. Extraído de https://sidra.ibge.gov.br/pesquisa/censo-demografico/demografico-2010/inicial

IBGE - Instituto Brasileiro de Geografia e Estatística. (2019). Desigualdades Sociais por Cor ou Raça no Brasil. Rio de Janeiro, v. 41, n. 323.12(81), p. 1-12.

IBGE - Instituto Brasileiro de Geografia e Estatística. (28 ago. 2019). Diário Oficial da União. Brasília, ed. 166, seção 1, p. 374.

IPEA - Instituto de Pesquisa Econômica Aplicada. (2019). O que mostra o retrato do Brasil? Ministério da Economia. Brasília-DF.

Jaccoud, L. (2008). O Combate ao Racismo e à Desigualdade: o desafio das políticas públicas de promoção da igualdade racial. In THEODORO, M. (2008). As Políticas Públicas e a Desigualdade Racial no Brasil: 120 anos após a abolição. Brasília: IPEA, p. 131- 166.

Lima, MC. (2008). Monografia: a engenharia da produção acadêmica. 2. ed. São Paulo: Saraiva. 
Martins, RM; Meneghel, SM. \& Wittkowski, JRT; wuo, AS. (2019). Políticas Afirmativas e Promoção da Equidade no Brasil: reflexões a partir do perfil de estudantes de direito e medicina. Jusbrasil. Extraído de https://advogadarosanemartins.jusbrasil.com.br/artigos/698775400/politicas-afirmativas-e-promocao-da-equidadeno-brasil? ref=serp

Mazzilli, S (2011). Ensino, pesquisa e extensão: reconfiguração da universidade brasileira em tempos de redemocratização do Estado. RBPAE - v. 27, n. 2, p. 205-221.

Meneghel, SM; Camargo, MS, \& Speller, P. (2018). De Havana a Córdoba: duas décadas de educação superior na América Latina. Blumenau: Editora Nova Letra. $287 \mathrm{p}$.

Nascimento, EP. (2012). Trajetória da sustentabilidade: do ambiental ao social, do social ao econômico. Estud. Av. vol. 26, n 74. São Paulo. Extraído de https://www.scielo.br/scielo.php?pid=S0103-40142012000100005\&script=sci arttext

Nilo, A., \& Almeida Pinto, F. (2017). Sobre Luzes e Sombras. In GRUPO DE TRABALHO DA SOCIEDADE CIVIL PARA AGENDA 2030 (2017). Relatório Luz da Agenda 2030 de Desenvolvimento Sustentável Síntese. 28 p.

Oliveira, ALM. (2019). Educação Superior brasileira no início do século XXI: inclusão interrompida? Tese de Doutorado-Campinas: UNICAMP.

Oliveira, SP. (2013) O Estatuto da Igualdade Racial. São Paulo: Selo Negro. 96 p.

ONU. (2015). Transformando Nosso Mundo: a Agenda 2030 para o Desenvolvimento Sustentável. Extraído de https://nacoesunidas.org/pos2015/agenda2030/

Quijano, A. (2005). Colonialidade do poder e eurocentrismo na América Latina. Buenos Aires: Clacso. Extraído de http://biblioteca.clacso.edu.ar/clacso/sursur/20100624103322/12_Quijano.pdf

Ristoff, D. (2014). O Novo Perfil do Campus Brasileiro. Avaliação, Campinas; Sorocaba, v. 19, n. 3, p. 723-747, nov. Extraído de www.scielo.br/pdf/aval/v19n3/ 10.pdf

Roma, JC. (2019). Os objetivos de desenvolvimento do milênio e sua transição para os objetivos de desenvolvimento sustentável. Ciência e Cultura, vol. 71, no 1, São Paulo. Extraído de http://cienciaecultura.bvs.br/scielo.php?script=sci arttext\&pid $=$ S0009-67252019000100011 
Ruano, JC. (2017). O desenvolvimento sustentável na educação superior. Propostas biomiméticas e transdisciplinar. Repositório digital de La Universidad Nacional de Educación UNAE. Extraído de http://repositorio.unae.edu.ec/handle/56000/611

Santos, H. et al. (1999). Políticas públicas para a população negra no Brasil. ONU, [Relatório ONU].

Sguissardi, V. (2015). Educação Superior no Brasil. Democratização ou massificação mercantil? Educ. Soc. v. 36, n.133, Campinas. Extraído de https://www.scielo.br/j/es/a/mXnvfHVs7a5gHBRkDSLrGXr/?lang=pt\&format=pdf

Souza, JF. (2018) Educação Superior na América Latina e Caribe: panorama e perspectivas cem anos após a Reforma de Córdoba. Revista Educação e Emancipação, São Luís, v. 11, n. 3, set./dez. DOI: http://dx.doi.org/10.18764/23584319.v11n3p91-122

Souza, PHG. \& medeiros, M. (2017) The Concentration of Income at the Top in Brazil, 2006-2014. Working Paper, n. 163. Brasília: Centro Internacional de Políticas para o Crescimento Inclusivo (IPC-IG).

Theodoro, M. (2008). As Políticas Públicas e a Desigualdade Racial no Brasil: 120 anos após a abolição. Brasília: IPEA, 176 p.

Trindade, H. (2000). Saber e poder: os dilemas da universidade brasileira. Estudos Avançados. n. 40, v. 14, set/dez. Extraído de http://www.scielo.br/pdf/ea/v14n40/v14n40a13.pdf

UNESCO. (2009). Conferência Mundial sobre Ensino Superior 2009. As Novas Dinâmicas do Ensino Superior e Pesquisas para a Mudança e o Desenvolvimento Social. Comunicado. Paris. Extraído de http://portal.mec.gov.br/index. php?option=com docman\&view=download\&alias=4512-conferencia-paris\&ltemid=30192

Wainer, J, \& Melguizo, T. (2018). Políticas de inclusão no ensino superior: avaliação do desempenho dos alunos baseado no Enade de 2012 a 2014. Educ. Pesq., v. 44, São Paulo. Extraído de https://www.scielo.br/scielo.php?pid=S1517-97022017005001103

Wittkowski, JRT, \& Meneghel, SM. (2019). Políticas de Ação Afirmativa na Educação Superior Brasileira: Entre Conquistas e Negações. Polyphōnia. Revista de Educación Inclusiva. Publicación científica del Centro de Estudios Latinoamericanos de Educación Inclusiva de Chile. Extraído de https://revista.celei.c//index.php/ PREl/article/view/162 


\section{BIONOTAS}

Stela Maria Meneghel. Mestrado e Doutorado em Educação pela UNICAMP, Docente do Programa de Pós-Graduação em Educação da Universidade Regional de Blumenau (FURB), Brasil. Colaborou na criação e implantação da UNILA e da UNILAB, e na coordenação dos Indicadores de Qualidade da Educação Superior do INEP/MEC.

E-mail: stmeneg@terra.com.br

https://orcid.org/0000-0002-7615-5784

Fabrício Filisbino: Mestrando em Educação pela Universidade Regional de Blumenau (FURB). Licenciado em Filosofia pela Unisul. Professor de Filosofia da rede estadual de Santa Catarina. Atua principalmente nos seguintes temas: Foucault, Agamben, Alteridade, Educação e Biopolítica.

E-mail: ffilisbino@furb.br

https://orcid.org/0000-0002-5130-4843

Ana Cristina Adry Moura de Argôllo. Mestranda em Educação pela FURB. Especialista em Direito Material e Processual do Trabalho. Coordenadora do Curso de Direito da Faculdade de llhéus.

E-mail: cristinaadry@gmail.com

https://orcid.org/0000-0002-6849-3572 